\title{
İrritable Bağırsak Sendromlu Hastalarda Gastrointestinal Semptomların Umutsuzluk ve Depresyon Düzeyine Etkisi
}

\section{The Effect of Gastrointestinal Symptoms on Hopelessness and Depression in Patients with Irritable Bowel Syndrome}

\author{
Zeynep ERDOĞAN ${ }^{\mathrm{a}}$,Mehmet Ali KURÇER ${ }^{\mathrm{b}}$, Beyhan BUDAK ${ }^{\mathrm{c}}$, Selim AYDEMIR ${ }^{\mathrm{d}}$
}

\begin{abstract}
ÖZ Amaç: Bu çalışma irritable bağırsak sendromu olan hastalarda gastrointestinal semptomların depresyon ve umutsuzluk düzeyine etkisini belirlemek amacıyla planlanmıştır. Gereç ve Yöntem: Çalışmanın yapıldığı üniversite hastanesinin gastroenteroloji polikliniğine IBS tanısı almış günde ortalama 3 hasta başvurmaktadır. Araştırmanın evrenini 01.03.2017-05.08.2017 tarihleri arasında polikliniğe başvuran 314 hasta, örneklemini ise 18 yaş ve üzeri, IBS tanısı almış, iletişim sorunu olmayan ve araştırmaya katılmayı kabul eden 209 birey oluşturmuştur. Veriler hastaların sosyodemografik özelliklerini içeren Hasta Tanıtım Formu, Gastrointestinal Semptom Değerlendirme Ölçeği(GSDÖ, Beck Depresyon Ölçeği(BDÖ) ve Beck Umutsuzluk Ölçeği(BUÖ) ile toplanmıştır. Verilerin değerlendirilmesinde yüzdelik, $t$ testi, kikare testi, ANOVA ve pearson korelasyon testi kullanılmıştır. Bulgular: Yaş ortalaması $40.69 \pm 14.0$ olan hastaların, ortalama hastalık süresi $6.0 \pm 1.3$ yıldır. Hastaların GSDÖ'nden aldıkları toplam puan ortalaması $52.0 \pm 1.65$ olup, orta düzeyde semptom şiddetine sahip oldukları

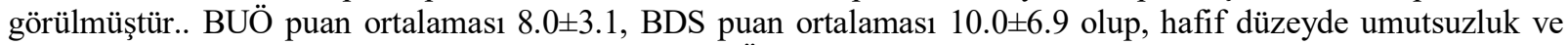
depresyon belirtisine sahip olduğu görülmüştür. GSDÖ alt boyutlarından karın ağrısı, reflü, hazımsızlık, diyare ve GSDÖ toplam puanıla BUÖ ve BDÖ arasında anlamlı bir ilişki saptanmazken, konstipasyon alt boyut puanıyla BUÖ arasında pozitif yönde orta düzeyde bir ilişki saptanmıştır. Benzer şekilde BDÖ ile konstipasyon alt boyut puanıyla pozitif yönde güçlü düzeyde bir ilişki saptanmıştır. Sonuç: Konstipasyon ile depresyon ve umutsuzluk arasında güçlü ve orta düzeyde bir ilişki saptanmıştır. Özellikle konstipasyonu olan hastaların depresyon ve umutsuzluk düzeyi açısından değerlendirilmesi gerekmektedir.
\end{abstract}

Anahtar Kelimeler: İrritable bağırsak sendromu, gastrointestinal semptom, depresyon,umutsuzluk

\begin{abstract}
Objective: The present study aimed to determine the effect of gastrointestinal symptoms on hopelessness and depression in patients with irritable bowel syndrome (IBS). Material and Methods: An average of 3 patients were admitted to the gastroenterology polyclinic of the university hospital where they worked. The universe of the study included 314 patients who presented at the clinic between March, 1st 2017 and August, 5th 2017, while the sample consisted of 209 patients who were aged 18 and older, were diagnosed with IBS, had no barriers to communication, and agreed to participate in the study. Data was collected using the Patient Identification Form containing the socio-demographic characteristics, the Gastrointestinal Symptom Rating Scale (GSRS), the Beck Depression Inventory (BDI), and the Beck Hopelessness Scale (BHS). Data was analyzed using percentiles, t-test, chi-square test, ANOVA, Pearson correlation, and regression analysis. Results: Mean age of the patients was $40.69 \pm 14.0$, while mean disease duration was $6.0 \pm 1.3$ years. Mean GSRS score was $52.0 \pm 1.65$, indicating moderate symptom severity. Mean BHS score was $8.0 \pm 3.1$ and mean BDI score was $10.0 \pm 6.9$, indicating mild hopelessness and depression. The abdominal pain, reflux, indigestion, and diarrhea subscale scores of the GSRS and the total GSRS score were not significantly correlated with the BHS and BDI scores $(p<0.05)$; while the constipation subscale score of the GSRS had a positive and moderate correlation with the BHS score ( $\mathrm{p}<0.0001 ; \mathrm{r}=0.24)$. The constipation subscale score of the GSRS also had a positive and strong correlation with the BDI score $(\mathrm{p}<0.0001$; $\mathrm{r}=0.41$ ). Conclusion: Constipation was strongly and moderately correlated with depression and hopelessness. Patients with constipation, in particular, should be screened for depression and hopelessness.
\end{abstract}

Keywords: Irritable bowel syndrome, gastrointestinal symptom, depression, hopelessness

\section{Giriş}

İrritabl bağırsak sendromu (IBS), bağırsak alışkanlıklarındaki değişikliklerle birlikte tekrarla-

yan karın ağrısı ile karakterize, maliyeti yüksek, potansiyel olarak yaşamı olumsuz eykileyen

Gelis Tarihi/Received: 28-02-2018 -Kabul Tarihi/Accepted:26-06-2018

a Dr. Öğretim Üyesi, BEÜ Ahmet Erdoğan Sağlık Hizmetleri Meslek Yüksekokulu,zeynerdogan@ hotmail.com,ORCID:0000-0002-7298-7559

b Prof. Dr, BEU Tıp Fakültesi Halk Sağlığı Anabilim Dalı,kurcer@hotmail.com,

c Uzman Hemşire İ.Ü-Cerrahpaşa Cerrahpaşa Tıp Fakültesi, Enfeksiyon Kliniği, , beyhankd@gmail.com

d Prof. Dr.Sağlık Uygulama ve Araştırma Merkezi Gastroentroloji Anabilim Dalı, selimaydemir@ @otmail.com

Sorumlu yazar /correspondence: Dr. Öğr Üyesi Zeynep Erdoğan, zeynerdogan@ hotmail.com,ORCID:0000-0002-7298-7559 
fonksiyonel bir gastrointestinal bozukluktur (1). IBS hastalığında belirtilerin tekrarlayıcı veya kalıcı olması, hastaların yaşam kalitesini önemli ölçüde etkileyebilir(2). IBS'nin ayrıca hastaların seyahat etmek, uyku, beslenme, cinsel işlevler, kişisel ilişkiler, aile, arkadaşlar ve iş ile ilgili roller gibi günlük aktiviteleri üzerine de olumsuz etkisi vardır (3-8). IBS tanısı almış bireylerde yüksek oranda fibromiyalji, kronik yorgunluk gibi komorbid somatik hastalıkların yanı sıra IBS semptomlarıla yüksek oranda ilişkili olan anksiyete, depresyon gibi psikiyatrik bozukluklar da bildirilmiştir(9). Anksiyete ve depresyon, gastrointestinal sistem hastaliklarından etkilenen hastalarda ortak bir özellik olarak karşımıza çıkmaktadır (10-11). Literatür incelendiğinde IBS hastalarında depresyon ve umutsuzluk yeterince araştırılmamıştır. Umutsuzluk; belirtilerin şidde-tinden dolayı ve tedavinin yetersizliği nedeniyle tüm IBS hastaları için önemli bir konu olarak vurgulanabilir (12). Ancak hastanın herhangi bir alternatif çözüm bulamaması durumunda, umutsuzluğun intihar konusunda depresyondan daha belirleyici olduğu bildirilmiştir (13). Umutsuzluk seviyesini bunun için bir belirteç olarak görmek gerektiği vurgulanmıştır(14). Dolayısıyla bu çalışma İBS hastalarında GISS semptom şiddetinin depresyon düzeyiyle birlikte umutsuzluk düzeyini nasıl etkilediğini belirlemek amacıyla planlanmıştır.

\section{Gereç ve Yöntem}

\section{Araştırmanın Evreni ve Örneklemi}

Tanımlayıcı tipteki bu çalışma bir üniversite hastanesi gastroenteroloji polikliniğine başvuran IBS tanısı almış hastalar üzerinde yapılmıştır. Araştırmanın evrenini 07.04.201705.11.2017- tarihleri arasında polikliniğe başvuran 314 hasta, örneklemini ise 18 yaş ve üzeri, IBS tanısı almış, iletişim sorunu olmayan ve araştırmaya katılmayı kabul eden 209 hasta oluşturmuştur.

\section{Veri Toplama Araçları}

Veriler, Hasta Tanıtım Formu, Gastrointestinal Semptom Değerlendirme Ölçeği (GSDÖ, Beck Depresyon Ölçeği (BDÖ) ve Beck Umutsuzluk Ölçeği (BUÖ) ile toplanmıştır.

\section{Gastrointestinal Semptom Değerlendirme Ölçeği (GSDÖ), gastrointestinal sistem bozukluk-}

larında sıklıkla görülen semptomları değerlendirmek üzere Revicki ve ark.(1998) tarafindan geliştirilmiş olup, ölçeğin Türkçe geçerlik ve güvenirliği Turan ve ark. (2017) tarafindan yapılmıştır(15-16). GSDÖ'de bireyin son bir haftada gastrointestinal sorunlar yönünden kendini nasıl hissettiği değerlendirilir . Reflü (2 soru), hazımsızlık (4 soru), diyare (3 soru), konstipasyon (3 soru) ve karın ağrısı (3 soru) olmak üzere 5 alt boyutu olan ölçek, toplam 15 soruyu içermektedir. GSDÖ'den alınan yüksek puanlar semptomların daha şiddetli olduğunu gösterir. Turan ve ark. (2017) GSDÖ cronbach alfa değerini 0.82 olarak bulmuşlardır. Bu çalışmada GSDÖ Cronbach alfa değeri 0.71 olarak bulundu.

Beck Umutsuzluk Ölçeği (BUÖ); Beck ve ark (1974) tarafindan geliştirilen, Durak ve ark(1994) tarafından geçerlilik ve güvenirliği yapılan BUÖ, ergen ve yetişkin bireylerin geleceğe dönük beklentilerini ölçmektedir (17-18). Durak ve ark. (1994) BUÖ'nin cronbach alfa değerini 0.85 olarak bulmuşlardır. Ölçek 20 maddeden oluşur ve maddeler 0-1 puanla puanlandırılır. Maddelerin seçenekleri "Evet", "Hayır" şeklindedir. Ölçeğin puanlanmasinda 11 maddenin $(2,4,7,9,11,12,14$, $16,17,18,20)$ evet, 9 maddenin $(1,3,5,6,8,10$, $13,15,19)$ hayır cevabı 1 puanla değerlen-dirilir. Ölçekten elde edilecek puan aralığ $0-20$ arasındadır. Ölçek puanının artması umutsuzluğun yüksek olduğunu gösterir. Çalışmamızda BUÖ'nin Cronbach alfa değeri 0,86 olarak bulundu.

Beck Depresyon Ölçeği; Beck ve ark.(1961) tarafindan geliştirilmiş olup, ülkemizde geçerlilik ve güvenilirlik çalışması, Hisli (1988) tarafından yapılmıştır, BDÖ cronbach alfası 0.80 olarak bulunmuştur(19-20). Çoktan seçmeli 21 soruluk, depresyonun şiddetini ölçmekte kullanılan bir araçtır. Alınacak en yüksek puan 63'tür. Toplam puanın yüksekliği depresyonun şiddetini gösterir. Çalışmamızda BDÖ’nün cronbach alfa değeri 0,87 olarak bulundu.

\section{Araştırmanın Etik Yönü:}

Çalışma öncesinde, Bülent Ecevit Üniversitesi Klinik Araştırmalar Etik Kurulu'ndan yazılı izin alındı (2017-32-08/03). Her hasta, çalışma hakkında bilgilendirildi ve hastalardan yazılı onay alındı. 


\section{İstatistiksel Analiz}

Veriler "Statistical Package for Social Sciences" (SPSS) programinda skewness ve kurtosis değerlerinin normal dağılım koşullarını sağlaması üzerine yüzdelikler, ortalamalar, standart sapmalar, $\mathrm{t}$ testi, ANOVA, regresyon analizi ve Pearson korelasyon testi kullanılarak değerlendirildi. İstatistiksel olarak anlamlılık için $\mathrm{p}<0.05$ yeterli kabul edildi.

\section{Bulgular}

Hastaların sosyo-demografik özellikleri Tablo 1'de verilmiştir. Yaş ortalaması $40.69 \pm 11.56$ olan IBS hastalarının, çoğunluğu kadın(\%58.9) olup, evli(\%63.2), ilköğretim mezunu (\%42.1), ev hanımı (\%29.7) ve orta düzeyde gelir durumuna (\%73.2) sahipti. Hastalık tanısı alma süresi ortalama $6.01 \pm 1.3$ yıl olarak hesapland.

Tablo 1. IBS Hastalarını Sosyo-Demografik ve Bazı T1bbi Özellikleri $(\mathrm{n}=209)$

\begin{tabular}{llrr}
\hline & Ort \pm SS & \multicolumn{2}{c}{ Min-Max } \\
\hline Yaş & \multicolumn{1}{c}{$40.6 \pm 14.03$} & \multicolumn{2}{c}{$18-79$} \\
\hline Hastalık tanı süresi & \multicolumn{1}{c}{$6.0 \pm 1.31$} & \multicolumn{2}{c}{$0-40$} \\
\hline & Değişkenler & \multicolumn{1}{c}{$\mathrm{n}$} & $\%$ \\
\hline Cinsiyet & Kadın & 123 & 58.9 \\
& Erkek & 86 & 41.1 \\
\hline Medeni durum & Bekar & 77 & 36.8 \\
& Evli & 132 & 63.2 \\
\hline Öğrenim durumu & Okuryazar değil & 10 & 4.8 \\
& İlköğretim & 88 & 42.1 \\
& Lise & 40 & 19.1 \\
& Lisans & 64 & 30.6 \\
& Lisansüstü & 7 & 3.3 \\
\hline Gelir durumu & Kötü & 20 & 9.6 \\
& Orta & 153 & 73.2 \\
& İyi & 36 & 17.2 \\
\hline Meslek & Ev Hanımı & 62 & 29.7 \\
& Işçi & 44 & 21.1 \\
& Memur & 30 & 14.4 \\
& Emekli & 12 & 5.7 \\
& Serbest meslek & 38 & 18.2 \\
& Öğrenci & 23 & 11.0 \\
\hline
\end{tabular}

IBS hastalarının GSDÖ, BUÖ ve BDÖ puanlarının dağılımı Tablo 2'de verilmiştir. Hastaların GSDÖ'den aldıkları toplam puan ortalaması $52.00 \pm 1.65$ olup, orta düzeyde semptom şiddetine sahipti. GSDÖ alt boyut puanları karın ağrısı, reflü, hazımsızlık, konstipasyon ve diyare olmak üzere sirasiyla $\quad 10.49 \pm 3.98, \quad 6.99 \pm 3.10, \quad 15.60 \pm 5.65$, $10.35 \pm 5.14$ ve $8.54 \pm 4.18$ ' dir. BUÖ puan ortalamas1 $8.00 \pm 3.16$, BDÖ puan ortalamas1 $10.00 \pm 6.9$ olup, hafif düzeyde umutsuzluk ve depresyon belirtisine sahiptirler.

Tablo 2. IBS Hastalarının Umutsuzluk, Depresyon ve Gastrointestinal Semptom Ölçeği Alt Boyut Puanlarının Dağılımı (n=209)

\begin{tabular}{lc}
\hline Ölçekler & Ort \pm SS \\
\hline BUÖ & $9.0 \pm 3.16$ \\
\hline BDÖ & $10.0 \pm 6.9$ \\
\hline Karın ağrıs1 & $10.5 \pm 3.98$ \\
\hline Reflü & $7.0 \pm 3.10$ \\
\hline Hazımsızlık & $15.6 \pm 5.65$ \\
\hline Konstipasyon & $10.3 \pm 5.14$ \\
\hline Diyare & $8.5 \pm 4.18$ \\
\hline GSDÖ toplam puan & $52.0 \pm 1.65$ \\
\hline
\end{tabular}

Hastaların sosyodemografik özelliklerine göre GSDÖ, BUÖ ve BDÖ puan ortalamalarının dağ $11 ı \mathrm{~m} ı$ Tablo 3'de verilmiştir. BDÖ puanı ile cinsiyet $(\mathrm{p}=0.004)$, medeni durum $(\mathrm{p}=0.003)$, eğitim durumu $(\mathrm{p}<0.0001)$, gelir düzeyi $(\mathrm{p}<0.0001)$ ve mesleği $(p<0.0001)$ arasında istatis-tiksel olarak anlamlı fark saptandı. Hastalık süresi ile BDÖ arasında pozitif yönde orta düzeyde anlamlı bir ilişki saptandı ( $\mathrm{p}<0.0001$; $\mathrm{r}: 0.526)$. Kadınların, bekarların, lisans mezunlarının, gelir düzeyi kötü olanların, öğrencilerin ve ev hanımlarının depresyon puanları daha yüksekti. Yaş ile BDÖ arasında istatistiksel olarak anlamlı olacak şekilde, negatif yönde zayıf bir iliş̧i saptanmış olup, yaş arttıkça depresyon puanla-rında azalma gözlenmiştir ( $\mathrm{p}<0.006$; $:-0.191)$.

Tablo 3'e göre BUÖ puanı ile medeni durum $(\mathrm{p}<0.001)$, eğitim durumu $(\mathrm{p}<0.05)$, gelir düzeyi $(\mathrm{p}<0.0001)$ ve meslek $(\mathrm{p}<0.0001)$ arasinda istatsitiksel açıdan anlamlı fark saptand. Bekarlar, lisansüstü öğrenimi olanlar, gelir düzeyini kötü olarak ifade edenler, serbest meslek sahibi olanlar ve öğrencilerin daha umutsuz oldukları görüldü. Yaş ile BUÖ arasında istatistiksel olarak anlamlı 
Tablo 3. Hastaların Sosyodemografik Özelliklerine Göre GSDÖ, BUÖ ve BDÖ Puan Ortalamalarının Dağılımı

\begin{tabular}{|c|c|c|c|c|c|c|c|c|}
\hline Değişkenler & BUÖ & BDÖ & Karın ağrısı & Reflü & Hazimsizlik & Konstipasyon & Diyare & GSDÖ \\
\hline $\begin{array}{l}\text { Yaş } \\
\mathbf{p}\end{array}$ & $\begin{array}{l}\mathrm{r}:-0.201 * * \\
\mathbf{p}<\mathbf{0 . 0 0 4}\end{array}$ & $\begin{array}{l}r=-0.191^{* *} \\
\mathbf{p}<\mathbf{0 . 0 0 6}\end{array}$ & $\begin{array}{l}r=0.023 \\
0.74\end{array}$ & $\begin{array}{l}r=0.072 \\
0.297\end{array}$ & $\begin{array}{l}\mathrm{r}=0.141 * \\
\mathbf{p}<\mathbf{0 . 0 4 1}\end{array}$ & $\begin{array}{l}r=-0.136^{*} \\
\mathbf{p}<\mathbf{0 . 0 4 9}\end{array}$ & $\begin{array}{l}\mathrm{r}=0.011 \\
0.877\end{array}$ & $\begin{array}{l}r=0.010 \\
0.882\end{array}$ \\
\hline $\begin{array}{l}\text { Cinsiyet } \\
\text { Kadın } \\
\text { Erkek } \\
\mathrm{p}\end{array}$ & $\begin{array}{l}7.70 \pm 3.76 \\
7.47 \pm 3.74 \\
0.66\end{array}$ & $\begin{array}{l}12.33 \pm 4.41 \\
8.29 \pm 3.26 \\
\mathbf{p}<\mathbf{0 . 0 0 4}\end{array}$ & $\begin{array}{l}10.37 \pm 4.32 \\
10.67 \pm 3.46 \\
\text { p:0.59 }\end{array}$ & $\begin{array}{l}7.17 \pm 4.05 \\
6.74 \pm 3.30 \\
p=0.55\end{array}$ & $\begin{array}{l}15.61 \pm 4.92 \\
15.59 \pm 4.28 \\
p=0.97\end{array}$ & $\begin{array}{c}11.48 \pm 4.25 \\
8.74 \pm 2.54 \\
\mathbf{p}<\mathbf{0 . 0 0 0}\end{array}$ & $\begin{array}{l}8.21 \pm 4.51 \\
9.01 \pm 3.68 \\
p=0.27\end{array}$ & $\begin{array}{l}52.86 \pm 11.42 \\
50.76 \pm 13.33 \\
p=0.36\end{array}$ \\
\hline $\begin{array}{l}\text { Medeni durum } \\
\text { Evli } \\
\text { Bekar } \\
\mathrm{p}\end{array}$ & $\begin{array}{l}6.93 \pm 2.78 \\
8.76 \pm 2.40 \\
\mathbf{p}<\mathbf{0 . 0 0 1}\end{array}$ & $\begin{array}{l}9.10 \pm 2.84 \\
13.35 \pm 1.54 \\
\mathbf{p}<\mathbf{0 . 0 0 3}\end{array}$ & $\begin{array}{l}10.64 \pm 3.29 \\
10.24 \pm 2.40 \\
0.48\end{array}$ & $\begin{array}{l}7.43 \pm 3.82 \\
6.23 \pm 2.44 \\
0.10\end{array}$ & $\begin{array}{l}16.69 \pm 4.56 \\
13.74 \pm 4.33 \\
\mathbf{p}<\mathbf{0 . 0 0 0}\end{array}$ & $\begin{aligned} 9.68 \pm 3.76 \\
11.50 \pm 4.44 \\
\mathbf{p}<\mathbf{0 . 0 1}\end{aligned}$ & $\begin{array}{l}8.22 \pm 3.30 \\
9.07 \pm 2.94 \\
0.25\end{array}$ & $\begin{array}{l}17.36 \pm 1.51 \\
15.02 \pm 1.71 \\
0.42\end{array}$ \\
\hline $\begin{array}{l}\text { Eğitim Durumu } \\
\text { Okur yazar değil } \\
\text { İlköğrenim } \\
\text { Lise } \\
\text { Lisans mezunu } \\
\text { Lisansüstü } \\
\mathbf{P} \\
\end{array}$ & $\begin{array}{l}6.90 \pm 2.42 \\
7.15 \pm 3.29 \\
6.82 \pm 3.07 \\
8.68 \pm 2.74 \\
8.85 \pm 1.57 \\
\mathbf{p}<\mathbf{0 . 0 4 8} \\
\end{array}$ & $\begin{array}{r}20.30 \pm 4.42 \\
9.56 \pm 3.40 \\
5.92 \pm 1.19 \\
14.31 \pm 5.17 \\
4.57 \pm 1.37 \\
\mathbf{p}<\mathbf{0 . 0 0 0}\end{array}$ & $\begin{array}{r}10.40 \pm 2.43 \\
11.32 \pm 3.41 \\
9.95 \pm 2.03 \\
9.82 \pm 2.34 \\
9.42 \pm 2.04 \\
0.14\end{array}$ & $\begin{array}{l}6.00 \pm 2.71 \\
8.11 \pm 3.54 \\
6.37 \pm 2.02 \\
6.01 \pm 2.41 \\
6.85 \pm 1.69 \\
0.108 \\
\end{array}$ & $\begin{array}{l}15.70 \pm 3.00 \\
17.69 \pm 3.68 \\
15.57 \pm 3.59 \\
12.95 \pm 3.00 \\
13.71 \pm 2.56 \\
\mathbf{p}<\mathbf{0 . 0 0 0} \\
\end{array}$ & $\begin{array}{r}10.80 \pm 3.47 \\
9.40 \pm 2.93 \\
9.50 \pm 2.61 \\
11.54 \pm 3.79 \\
15.71 \pm 2.49 \\
\mathbf{p}<\mathbf{0 . 0 0 4} \\
\end{array}$ & $\begin{array}{l}7.70 \pm 2.34 \\
9.12 \pm 3.69 \\
8.02 \pm 2.42 \\
8.53 \pm 3.68 \\
5.42 \pm 2.04 \\
0.369 \\
\end{array}$ & $\begin{array}{l}50.60 \pm 10.52 \\
55.67 \pm 11.66 \\
49.42 \pm 10.76 \\
48.87 \pm 11.03 \\
51.14 \pm 6.12 \\
0.102\end{array}$ \\
\hline $\begin{array}{l}\text { Gelir Durumu } \\
\text { Kötü } \\
\text { Orta } \\
\text { İyi } \\
\mathrm{p} \\
\end{array}$ & $\begin{array}{l}9.28 \pm 2.87 \\
7.55 \pm 3.67 \\
5.10 \pm 2.74 \\
\mathbf{p}<\mathbf{0 . 0 0 0}\end{array}$ & $\begin{array}{l}14.16 \pm 3.95 \\
10.90 \pm 4.72 \\
2.55 \pm 0.90 \\
\mathbf{p}<\mathbf{0 . 0 0 0} \\
\end{array}$ & $\begin{array}{l}12.20 \pm 4.52 \\
10.54 \pm 3.87 \\
9.36 \pm 3.87 \\
\mathbf{p}<\mathbf{0 . 0 3 6} \\
\end{array}$ & $\begin{array}{l}11.60 \pm 5.46 \\
6.82 \pm 3.47 \\
5.16 \pm 2.26 \\
\mathbf{p}<\mathbf{0 . 0 0 0}\end{array}$ & $\begin{array}{l}18.65 \pm 4.28 \\
15.99 \pm 3.49 \\
12.27 \pm 2.15 \\
\mathbf{p}<\mathbf{0 . 0 0 0} \\
\end{array}$ & $\begin{array}{l}7.10 \pm 2.68 \\
10.52 \pm 4.09 \\
11.47 \pm 4.98 \\
\mathbf{p}<\mathbf{0 . 0 0 7} \\
\end{array}$ & $\begin{array}{l}11.45 \pm 4.12 \\
8.77 \pm 2.33 \\
5.91 \pm 1.11 \\
\mathbf{p}<\mathbf{0 . 0 0 0}\end{array}$ & $\begin{array}{l}61.00 \pm 12.07 \\
52.66 \pm 14.82 \\
44.19 \pm 12.68 \\
\mathbf{p}<\mathbf{0 . 0 0 1} \\
\end{array}$ \\
\hline $\begin{array}{l}\text { Meslek } \\
\text { Ev hanımı } \\
\text { İşçi } \\
\text { Memur } \\
\text { Emekli } \\
\text { Serbest meslek } \\
\text { Öğrenci } \\
\text { p }\end{array}$ & $\begin{array}{l}7.75 \pm 2.01 \\
5.00 \pm 1.32 \\
8.08 \pm 2.20 \\
7.78 \pm 2.37 \\
9.21 \pm 1.04 \\
9.50 \pm 2.50 \\
\mathbf{p}<\mathbf{0 . 0 0 0}\end{array}$ & $\begin{array}{l}14.56 \pm 7.12 \\
3.29 \pm 0.61 \\
12.80 \pm 5.95 \\
5.08 \pm 2.30 \\
10.52 \pm 4.67 \\
14.65 \pm 3.74 \\
\mathbf{p}<\mathbf{0 . 0 0 0}\end{array}$ & $\begin{array}{l}10.70 \pm 3.64 \\
11.13 \pm 4.43 \\
10.23 \pm 2.47 \\
10.25 \pm 2.37 \\
9.36 \pm 2.07 \\
11.04 \pm 3.69 \\
0.424\end{array}$ & $\begin{array}{l}7.83 \pm 2.68 \\
7.34 \pm 2.44 \\
6.60 \pm 1.95 \\
7.16 \pm 2.58 \\
5.63 \pm 1.68 \\
6.73 \pm 2.01 \\
0.436\end{array}$ & $\begin{array}{l}16.70 \pm 4.96 \\
16.25 \pm 4.35 \\
15.20 \pm 3.22 \\
18.16 \pm 2.82 \\
13.28 \pm 4.61 \\
14.43 \pm 4.99 \\
\mathbf{p}<\mathbf{0 . 0 2 3}\end{array}$ & $\begin{array}{l}9.96 \pm 3.15 \\
9.25 \pm 3.74 \\
10.66 \pm 3.87 \\
7.91 \pm 2.48 \\
10.52 \pm 3.51 \\
14.13 \pm 3.95 \\
\mathbf{p}<\mathbf{0 . 0 0 3}\end{array}$ & $\begin{array}{l}7.85 \pm 2.51 \\
10.09 \pm 3.02 \\
9.13 \pm 2.81 \\
8.16 \pm 2.24 \\
7.74 \pm 2.14 \\
8.73 \pm 2.87 \\
0.200\end{array}$ & $\begin{array}{l}53.03 \pm 10.52 \\
54.06 \pm 11.74 \\
51.83 \pm 10.06 \\
51.66 \pm 9.57 \\
46.28 \pm 8.97 \\
55.08 \pm 11.17 \\
0.281\end{array}$ \\
\hline $\begin{array}{l}\text { Hastalık süresi } \\
\text { p }\end{array}$ & $\begin{array}{l}\mathrm{r}: 0.128 \\
0.066\end{array}$ & $\begin{array}{l}\mathrm{r}: 0.526^{* * *} \\
\mathbf{p}<\mathbf{0 . 0 0 0}\end{array}$ & $\begin{array}{l}\mathrm{r}: 0.034 \\
0.624 \\
\end{array}$ & $\begin{array}{l}\mathrm{r}: 0.00 \\
0.996 \\
\end{array}$ & $\begin{array}{l}r:-0.101 \\
0.146\end{array}$ & $\begin{array}{l}\mathrm{r}: 0.243^{* *} \\
\mathbf{p}<\mathbf{0 . 0 0 0}\end{array}$ & $\begin{array}{l}r:-0.044 \\
0.524\end{array}$ & $\begin{array}{l}\mathrm{r}: 0.036 \\
0.604\end{array}$ \\
\hline
\end{tabular}


Tablo 4. Hastaların BUÖ, BDÖ ve GSDÖ Alt Boyut Puanları Arasındaki İlişkinin Dağılımı

Değişkenler BUÖ BDÖ

\begin{tabular}{|c|c|c|}
\hline Karın ağrıs1 & $\mathrm{p}=0.62$ & $\mathrm{p}=0.09$ \\
\hline Reflü & $\mathrm{p}=0.99$ & $\mathrm{p}=0.95$ \\
\hline Hazımsızlık & $\mathrm{p}=0.14$ & $\mathrm{p}=0.13$ \\
\hline Konstipasyon & $\mathrm{r}=0.243^{* *}$ & $\mathrm{r}=0.41 * *$ \\
\hline Diyare & $\mathrm{p}=0.52$ & $\mathrm{p}=0.73$ \\
\hline $\begin{array}{l}\text { GSDÖ toplam } \\
\text { puan }\end{array}$ & $p=0.604$ & $\mathrm{r}=0.156^{*}$ \\
\hline BDÖ & \multicolumn{2}{|c|}{$\mathrm{p}=0.000 \mathrm{r}=0.526$} \\
\hline
\end{tabular}

olacak şekilde, negatif yönde zayıf bir ilişki saptanmış olup, yaş arttıkça umutsuzluk puanlarında azalma gözlendi. ( $<<0.004$; r:-0.201).

Hastaların GSDÖ ölçeği alt boyutlarına göre sosyodemografik özellikler incelendiğinde; cinsiyet ile konstipasyon, medeni durum ile hazımsızlık ve konstipasyon, eğitim düzeyi ile hazımsızlık ve konstipasyon, gelir düzeyi ile GSDÖ'nin tüm alt boyutları ve toplam GSDÖ puanı, meslekle hazımsızlı ve konstipasyon alt boyutları arasında anlamlı ilişki saptanmıştır ( $\mathrm{p}<0.05)$.

Kadınların konstipasyon alt boyut puanlarının, erkeklere göre yüksek olduğu $(\mathrm{p}=0.000)$, evli olanların bekarlara göre hazımsızlık $(\mathrm{p}<0.0001)$ puanları, bekarların ise evlilere göre konstipasyon $(\mathrm{p}<0.0001)$ alt boyut puanlarının daha yüksek olduğu görüldü.

Lisans ve lisansüstü öğrenim mezunlarının anlamlı olacak şekilde hazımsızlık puanları daha düşük $(\mathrm{p}<0.0001)$, ancak konstipasyon puanları daha yüksek bulunmuştur ( $\mathrm{p}=0.004)$. Gelir düzeyi düşük olanların konstipasyon puanı hariç, tüm GSDÖ alt boyut puanları ve GSDÖ toplam puanı yüksek bulunmuştur $(p<0.0001)$. Mesleğe göre bakıldığında; emeklilerin hazımsızlıkları puanlar $1(p<0.02)$, öğrencilerin ise konstipasyon puanları $(p<0.003)$ diğer meslek gruplarına göre yüksek çıkmıştır.

Yaşla hazımsızlık puanı arasında pozitif yönde, zayıf $(\mathrm{p}<0.041 ; \mathrm{r}=0.141)$, konstipasyonla negatif yönde zayıf bir ilişki saptanmışıır( $<<0.049$; $r=-0.136)$. Hastalık süresiyle konstipasyon arasinda pozitif yönde, zayıf bir ilişki saptanmıştır $(p<0.000 ; r=0.243)$. Hastaların BUÖ, BDÖ ve
GSDÖ alt boyut puanları arasındaki ilişkinin dağılımı Tablo 4'de verilmiştir.

GSDÖ alt boyutlarından karın ağrısı, reflü, hazımsızlık, diyare ve GSDÖ toplam puanıla BUÖ ve BDÖ arasında anlamlı bir ilişki saptanmazken ( $\mathrm{p}<0.05)$; konstipasyon alt boyut puanıla BUÖ arasında pozitif yönde zayıf düzeyde bir ilişki saptanmıştır $(\mathrm{p}<0.0001 ; \mathrm{r}=0.24)$. BDÖ ile de aynı şekilde sadece konstipasyon alt boyut puanıla pozitif yönde orta düzeyde bir ilişki saptanmıştır ( $<<0.0001 ; r=0.41)$. GSDÖ ile BDÖ puanlar1 arasında zayıf $(p<0.02 ; r=0.156)$, BUÖ ile BDÖ puanları arasında ise çok kuvvetli pozitif yönde ilişki bulunmuştur $(\mathrm{p}<0.000 ; \mathrm{r}=0.526)$.

\section{Tartışma}

IBS tanısı almış hasta bireylerde sosyodemografik özelliklere göre gastrointestinal semptomlar, depresyon ve umutsuzluk düzey-lerinin incelendiği herhangi bir çalışmaya da rastlanılmamıştır. Dolayısıyla bu bölümde çalışma bulgularımız gastrointestinal bozukluğu olan diğer hasta gruplarının sonuçlarıyla tartışılacaktır. Bu durum çalışmamızın sınırlılıklarından biri olarak görülebilir ancak yeni çalışmaların planlanmasına katkı sağlayacağ 1 düşünülmektedir.

$\mathrm{Bu}$ çalışmada kadınların, bekarların, üniversite mezunlarının, gelir düzeyi kötü olanların, öğrencilerin ve ev hanımlarının depresyon puanları daha yüksek bulunmuştur. Yaş ile depresyon arasında negatif yönde zayıf bir ilişki saptanmıştır. Addolorato ve ark. nın (2008) iç hastalıkları polikliniğine başvuran gastrointestinal problemi olan hastalarda anksiyete ve depresyon durumunu incelediği çalışmasında kadınların anksiyete ve depresyon düzeylerini daha yüksek bulmuştur(21). Alasoimi ve ark. (2014)'da gastroenteroloji polikliniğine başvuran hastaların anksiyete ve depresyon düzeylerini kadınlarda, öğrenim ve gelir düzeyi düşük olanlarda yüksek bulmuştur (22). Bu sonuçlar örneklem grubu farklılığına rağmen bizim çalışmamızla benzerlik göstermektedir. Bilindiği gibi IBS; sürekli veya yineleyici karın ağrısı ya da karında rahatsızlık hissi ile karakterize, hastada defekasyon ile rahatlamanın görüldüğü, yakınmaları organik yönden açıklayacak fiziksel veya laboratuar bulgularının netlik kazanmadığı bir hastalıktır.

Dolayısıyla bu tanımlama ve sindirim kanalı ile emosyonel durumlar arasındaki yakın ilişki, İBS'nun işlevsel gastroenterolojik bir hastalık 
olarak kabul edilmesine neden olmuştur (23). Sonuç olarak bu çalışmada da özellikle konstipasyonu olan hastalarda depresyona rastlanılması benzer çalışmalarla paralellik göster-miştir. Gorard ve ark.(1996) çalışmasında uzamış barsak pasajı ile depresyon ilişkisini ortaya koymuşlardır (24). Başka bir çalışmada da idiyopatik konstipasyonu olan hastalarda, bu çalışmayla uyumlu olarak depresyon ve konstipasyon ilişkisi olduğu bildirilmiştir (25). Haug ve ark. (2002)'da 20 yaş ve üzeri toplumda yaptıkları araştırmada bu çalışmayla benzer şekilde konstipasyon ile depreşyon arasında ilişki saptarken, bu çalışmadan farklı olarak diyare ve mide yanmasiyla depresyon arasında da ilişki saptamışlardır. Bouchoucha ve ark. (2014)'nın çalışmasında ise konstipasyonu baskın olan İBS tanılı bireylerin fonksiyonel konstipasyonlu bireylerden daha depresif oldukları aynı şekilde gaz ve karın ağrısı ile depresyon arasında ilişki olduğunu bildirmişlerdir (27). IBS hastalarında semptom şiddeti, yaşamla mücadele ve tedaviden doyum sağlayamama gibi nedenlerin, umutsuzluğa yol açtığı vurgulanmaktadır (14). Bununla birlikte, umutsuzluğun, hastanın sorununa herhangi bir alternatif çözüm bulunmaması durumunda depresyonla birlikte intihara da yönelimi artırdığı bildirilmiştir (14). Umutsuzluk, Kuzey Amerikan Hemşirelik Tanıları Derneği (North Amerikan Nursing Diagnosis AssociationNANDA) tarafından "problemleri çözmek ve istenen amaca ulaşmak için hiçbir alternatifin ya da bireysel tercihinin olmadığını düşünen, amaçlar oluşturmak için enerjisini kendi kendine harekete geçiremeyen bir bireydeki sürekli ve subjektif bir duygusal durum" olarak tanımlanmıştır (28). Bu çalışmada hastaların hafif düzeydeki depresif ve umutsuzluk belirtisine sahip olmalarına rağmen, konstipasyonlu hastalarin depresyon ve umutsuzluk düzeyleri anlamlı düzeyde yüksektir. Umutsuzluk düzeyi ile konstipasyonunun birlikte incelendiği çalışmaya literatürde rastlanmamıştır. Ancak umutsuzluk ve depresyonun birlikte görüldüğü bildirilmiştir (29). Sonuç olarak bu çalışmada da umutsuzluk düzeyi ile depresyon düzeyi arasında pozitif yönde kuvvetli ilişki saptanmıştır.

\section{Sonuç}

Bu çalışmada IBS tanılı bireylerde depresyon ve umutsuzluk puanlarının sosyodemografik özelliklerden etkilendiği, gastrointestinal semptomlardan konstipasyonu olan hastaların daha fazla depresif ve umutsuz oldukları saptanmıştır. Kronik hastalığı olan bireyin bozulan dengesini yeniden kurabilmesi, sağlığı ile ilgili sorunlarını çözümleyebilmesi için normal bir yetişkinden daha çok desteklenmeye, kabullenilmeye, anlaşılmaya ve anlamlı açıklamalara gereksinimi vardır (28). Dolayısıyla IBS'nin kronik bir hastalık olduğu göz önünde bulundurularak hastalar GIS semptomlar yönünden değerlendirilmesini, özellikle bu çalışmada bulduğumuz konstipasyon ve depresyon bulguları arasındaki bu ilişkinin, farklı örneklem gruplarında yapılacak çalışmalarla da doğrulanmasinı önermekteyiz.

\section{KAYNAKLAR}

1. Longstreth GF, Thompson WG, Chey WD, Houghton LA, Mearin F, Spiller RC. Functional bowel disorders. Gastroenterology. 2006;130(5):1480-91.

2. Drossman DA, Camilleri M, Mayer EA, Whitehead WE. AGA technical review on irritable bowel syndrome. Gastroenterology.2002; 123(6):2108-31 .

3. Dancey CP, Backhouse S. Towards a better understanding of patients with irritable bowel syndrome. J Adv Nurs.1993;18(9):1443-50.

4. Drossman DA, Li Z, Andruzzi E, Temple RD, Talley NJ, Thompson WG, Whitehead WE, Janssens J, Funch-Jensen P, Corazziari E, et al.U.S. householder survey of functional gastrointestinal disorders. Prevalence, sociodemography, and health impact. Dig Dis Sci. 1993; 38(9):1569-80.

5. Wells NE, Hahn BA, Whorwell PJ.Clinical economics review: irritable bowel syndrome. Aliment Pharmacol Ther. 1997; 1997;11(6):1019-30.

6. Hahn BA, Yan S, Strassels S. Impact of irritable bowel syndrome on quality of life and resource use in the United States and United Kingdom. Digestion. 1999;60(1):77-81.

7. Gralnek IM, Hays RD, Kilbourne A, Naliboff B, Mayer EA. The impact of irritable bowel syndrome on health-related quality of life. Gastroenterology. 2000;119:654-60.

8. Hungin APS, Tack J, Mearin F, Whorwell J, Dennis E, Barghout V. Irratable bowel syndrome (IBS): prevalence and impact in the USA - the truth in IBS (T-IBS) survey Am J Gastroenterol. 2002;97:S280-S281. 
9. Gros DF, Antony MM, McCabe RE, Swinson RP. Frequency and severity of the symptoms of irritable bowel syndrome across the anxiety disorders and depression. Journal of Anxiety Disorders. 2009;23(2): 290-296.

10. Van Kerkhoven LA, van Rossum LG, van Oijen MG, Witteman EM, Jansen JB, Laheij RJ, Tan AC. Anxiety, depression and psychotropic medication use in patients with persistent upper and lower gastrointestinal symptoms. Aliment Pharmacol Ther. 2005;21(8):1001-6.

11. Levy RL, Olden KW, Naliboff BD, Bradley LA, Francisconi C, Drossman DA, Creed F. Psychosocial aspects of the functional gastrointestinal disorders. Gastroenterology. 2006;130(5):1447-58.

12. Hitchcock LS, Ferrell BR, McCaffery M. The experience of chronic nonmalignant pain. $\mathrm{J}$ Pain Symptom Manage. 1994;9(5):312-8.

13. Maris RW. Suicide. Lancet. 2002;360(9329):319-26.

14. Miller V, Hopkins L, Whorwell PJ. Suicidal ideation in patients with irritable bowel syndrome. Clin Gastroenterol Hepatol. 2004;2(12):1064-8.

15. Revicki DA, Wood M, Wiklund I, Crawley J. Reliability and validity of the Gastrointestinal Symptom Rating Scale in patients with gastroesophageal reflux disease. Qual Life Res.,1998; 7(1):75-83.

16. Turan N, Aștı Atabek T., Kaya N. Reliability and validity of the Turkish version of the Gastrointestinal Symptom Rating Scale. Gastroenterol Nurs., 2017; 40(1):47-5540(1): 47-55.

17. Beck AT, Weissman A, Lester D, Trexler L. The measurement of pessimism: the hopelessness scale. J Consult Clin Psychol.,1974; 42(6):861-5.

18. Durak A. Validity and reliability of Beck hopelessness scale. J Turk Psychol.,1994; 9:111.

19. Beck AT, Ward CH, Mendelson M, et al. An inventory for measuring depression. Arch Gen Psychiatry 1961; 4: 561.

20. Hisli N (1989). Beck Depresyon envanteri'nin üniversite öğrencileri için geçerliği ve güvenirliği. Psikoloji Dergisi 7(23): 3-13.

21. Addolorato G, Mirijello A, D'Angelo C, Leggio L, Ferrulli A, Abenavoli L, Vonghia L,
Cardone S, Leso V, Cossari A, Capristo E, Gasbarrini G. State and trait anxiety and depression in patients affected by gastrointestinal diseases: psychometric evaluation of 1641 patients referred to an internal medicine outpatient setting. Int J Clin Pract. 2008; 62(7):1063-9. doi: 10.1111/j.1742-1241.2008.01763.x.

22. Alosaimi FD, Al-Sultan O, Alghamdi Q, Almohaimeed I, Alqannas S. Association of help-seeking behavior with depression and anxiety disorders among gastroenterological patients in Saudi Arabia. Saudi J Gastroenterol. 2014;20(4):233-40.

23. Eker MÇ, Donat Eker Ö. Depresyon ve irritabl barsak sendromu birlikteliğinin nörobiyolojisi. Psikiyatride Güncel Yaklaşımlar. 2009; 1:120-131

24. Gorard DA, Gomborone JE, Libby GW, Farthing MJ. Intestinal transit in anxiety and depression. Gut 1996; 39: 551-555

25. Cheng C, Chan AO, Hui WM, Lam SK. (Coping strategies, illness perception, anxiety and depression of patients with idiopathic constipation: a population-based study. Aliment Pharmacol Ther. 2003;18(3):319-26.

26. Haug TT, Mykletun A, Dahl AA. Are anxiety and depression related to gastrointestinal symptoms in the general population?, Scandinavian Journal of Gastroenterology, 2002; 37(3): 294-298,

27. Bouchoucha M, Hejnar M, Devroede G, Boubaya M, Bon C, Benamouzig R. Patients with irritable bowel syndrome and constipation are more depressed than patients with functional constipation. Digestive and Liver Disease. 2014; 46(3):213-18.

28. Bayramova N., Karadakovan A. Kronik hastalığı olan bireylerin umutsuzluk durumlarının incelenmesi. Atatürk Üniv. Hemşirelik Yüksekokulu Dergisi,2004; 7(2) 39-47.

29. Fanaj N, E.Melonashi E, Drevinja F, Haxhibeqiri SH. Depression, anxiety, hopelessness and self-esteem in a clinical sample of adolescents in Kosovo. European Psychiatry. 2015; 30(1):1189. 